\title{
Blended Learning Concept and its Applications to Engineering Education
}

\author{
Cosmin Porumb, Sanda Porumb, Bogdan Orza and Aurel Vlaicu
}

Centre for Multimedia Technologies and Telecommunications, 15 Daicoviciu, 400020 Cluj-Napoca, Romania

\{cosmin.porumb, sanda.porumb, bogdan.orza, aurel.vlaicu\}@com.utcluj.ro Keywords: blended learning, engineering education, blended learning gap, blended learning
bridge, collaborative learning, blended assessment.

\begin{abstract}
The technical educational act means theory and practice, individual study, group-based projects or experimental work that involves equipment, simulation/emulation software packages and laboratory applications. In order to develop advanced e-learning tools and integrate them within online platforms for higher and postgraduate engineering education, new methodologies should be taken into consideration: project- and problem based learning, virtual laboratory (remote access to laboratory infrastructure and task evaluation) or remote assistance for diploma projects and mobility grants. This paper presents new blended learning concepts and approaches and the manner they can be adopted in engineering education, by using the symbiotic computing paradigms adapted to blended learning, especially blended learning gap and blended learning bridge.
\end{abstract}

\section{Introduction and Related Works}

In recent years, with the advances of the Internet and e-learning technologies, a blended mode of learning, which effectively combines the traditional face-to-face learning and e-learning, has evolved. Yet, this blended learning mode is not widely adopted in higher and postgraduate education programmes in engineering. One major reason is that teachers are not familiar with the practices of creating and delivering same courses in a mix of real classroom and virtual environment. Another important aspect is that many teachers still do not consider the e-learning methodologies stable enough and powerful for engineering, especially for practice activities such as laboratory and project completion. The third reason is that academic staff considers the act of teaching/learning engineering as more than individual study and online assessment, facilities provided by current e-learning solution.

Recent studies illustrate that students learn effectively by actively participating in the learning process, discussing among their peers and by discovering the concepts and facts on their own by experiencing them. In addition they are found to be more interactive in expressing their views about a topic in online learning. Most of the e-Learning systems found today are content centric and they do not provide a personalized learning environment for the students depending on their learning styles, interests and abilities [1]. Thamarai Selvi [1] analysed the effects of using blended learning approach that encompasses active learning and collaborative learning based on a learning cloud environment that supports and satisfies both "student centred" and "teacher centred" learning/teaching approaches. The main goals was to assure a personalized learning environment by providing differentiated instruction based on the students learning styles and grant the expected quality of learning while the cloud computing infrastructure enables users to access all the resources and applications as services anywhere and anytime [1].

Engineering consists of lecture attendance, project development, hands-on laboratory-based activities and computer simulation work. This way, the educational act can be considered as learnercentred. Manseur [2] presented the synchronous distance learning concept (SDL) and its application to Electric and Computer Engineering and Mathematics. Students follow lectures live via videoconferencing but they attend laboratory sessions taught by on-site faculty. The advanced technology has been used for linking the local and the remote classrooms: the lecturer teaching in one location is videotaped and can be seen on a TV screen in the other classroom live. If the SDL 
environment is an excellent solution for blended teaching activities, it cannot provide the same flexibility for practice such as hands-on experimentation and other laboratory applications. It is difficult to conduct practice activities without access to often expensive equipment and components and competent on-site laboratory tutors. In order to support practice activities the lab SDL environment consists of two sets of fully equipped and staffed laboratories, one on each end of the SDL-connected campuses [2].

Qiu [3] proposed a blended learning environment that implements the face-to-face teaching and elearning capabilities in Advanced Software Engineering. A set of integrated projects was selected as stimulus to learning. Both inter- and intra-group collaborative learning are encouraged. The survey conducted at the end of the course showed that students accept the problem-based learning very well, and their academic achievements were also better than expected. The Qui's methodology consisted of grouping students in teams, dividing the semester in project phases and developing the project using iterations [3].

Leone [6] proposed a language blended learning environment (LBLE) adopted at the University of Wollongong, Australia, and an online course for $\mathrm{PhD}$ students at the Università Politecnica delle Marche, Italy. LBLE platform could provide a distributed learning environment that enables students to follow face to face classes. The sessions were hands-on; learning-by-doing was facilitated by individual or/and group tasks that students carried out with the different tools available in the platform: chat, joint web browsing, desktop sharing and sub-cyber classrooms, enriched with various mark-up tools [6].

The studies and technologies presented above enable the teaching staff to conduct wide classes that involve students located in different places and allow the teacher-digital resource (educational material) interaction and teacher-student real-time collaboration. In addition, they enable teachers and students to share educational resources, concepts and ideas, among the classes. Another important part of the collaborative learning act is related to the problem and project based learning. Problem solving plays a critical role in knowledge building while exercises mean theory review and practice, as well as discussions with colleagues and instructors. The team projects require continuous study, individual effort and telework, arguing and sustaining of ideas and concepts, new methods and algorithms, then putting the individual contributions together as a whole, including the results of entire team.

This paper does not propose a complex survey of e-learning platforms and their use in engineering education. It uses the approaches illustrated in [7] and [8] related to the functionality, standards, contents creation, institutional support of e-learning platforms adopted in engineering education and presents several solutions for the problems faced when designing and implementing a complex framework, which complies with enhanced blended learning approaches. In this way, it should support remote teaching, collaborative learning, especially problem and project based learning, and blended assessment, including evaluation during the wide classes, at the end of each teaching module and students' contributions in project completion or laboratory activities. It is organized as follows: the introduction and related works are presented in Section I. Section II is dedicated to defining the advanced blended learning approaches to be implemented for remote teaching, collaborative learning and blended assessment. Section III consists of technological aspects related to the development of a flexible blended learning system dedicated to engineering education. Section IV highlighted the experimental results achieved when customizing the blended learning environment in engineering. In conclusion, the authors underline the importance of symbiotic computing and blended learning concepts for extending the traditional education act outside the classroom or laboratory by using the advanced technologies.

\section{Advanced Blended Learning Approaches}

A laborious research in engineering education enables the authors to identify some important issues regarding the delivery of technical programmes in a blended mode. Most of them are related to the student-teacher interaction, student's satisfaction, responsibility and control during the teaching/learning processes, and monitoring of study progress. For this reason, the modern 
techniques of education in colleges and universities include the face-to-face and Internet-based teaching/learning modes and the manner of getting them together in order to extend the traditional system and make the virtual platforms and their tools as a part of the real educational environment. The mentioned issues can be defined as a lack of mutual cognition between real educational space (RS) and virtual educational environment (VE) modelled by Sugawara [4] as e-Gap. Due to e-Gap, the degree of end-users' satisfaction is really low while they cannot receive suitable services they require. For this reason, e-Gap can be defined as the difference between the expectations and disappointments of the real educational system. One of reasons of the e-Gap is a lack of functions to find relationships between end-user requests and information resources and services developed in the virtual environment, rather than a lack of technologies to develop advanced functions in the virtual environment [4]. In addition, Koruda [5] brings the virtual reality concepts in the virtual collaboration field and proposes the 2D characters for representing the attendees, virtual blackboard component for resource sharing and virtual laser for annotation and live demonstration. In order to increase the efficiency of such virtual environment the virtual collaboration and application sharing are according to the physical interaction between the objects that define the applications while the distributed process representation in real time manner as $2 / 3 \mathrm{D}$ objects in virtual space.

Another way of blended learning. The traditional blended learning presents the face-to-face teaching and Internet-based learning like two different processes that never happen simultaneously. During the research study, we identified the students' main requests have been related to pro-active attendance to courses from anywhere, as well as the review of teacher's course presentation anytime. For these reasons, the definition of a blended learning model that includes both acts simultaneously happening will not be easily adopted in higher engineering education. Figure 1 illustrates a blended learning model that defines these requirements and enables the delivery of teaching simultaneously in real educational space (real classroom) and Internet-based educational environment.

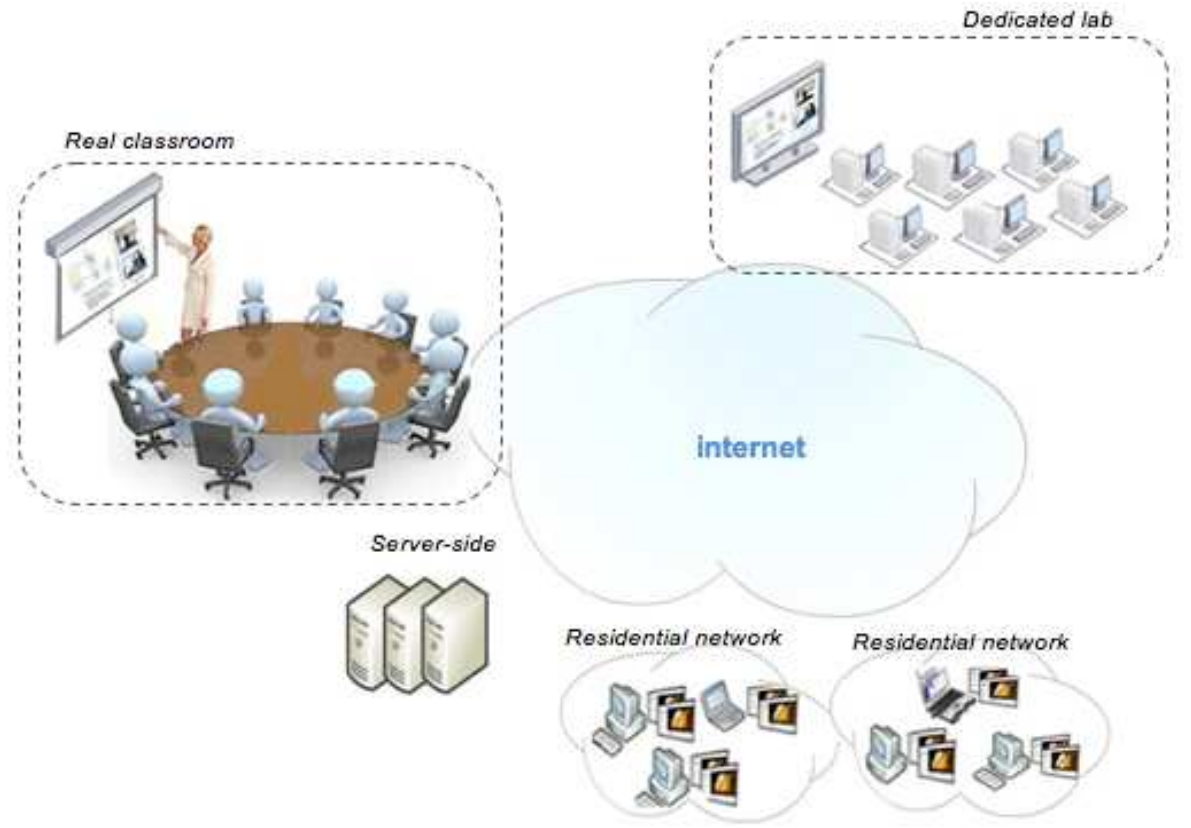

Fig. 1 - Blended learning model

The blended learning gap can be defined as the report between students' and teachers' expectations and the set of features provided by such a complex educational infrastructure. Analogue, the authors define the blended learning bridge as a set of interactive learning tools easy to adopt in the main educational forms, which minimize the differences between the real educational space and virtual environment. This way, the students interested in attending the course in the classroom will be presented in the real space, such as classroom or remote laboratories, and can interact with the class in a real manner. The ones that want to attend the class from home or others located at their work 
place can use the interactive learning tools, running on web browsers and native mobile applications, in order to virtually interact with the class. In the same manner, the teachers can use the notebooks, tablets, video projectors or smart boards for presenting the educational materials and interact with the real and virtual spaces.

Blended assessment - a new evaluation approach. The blended assessment model presented in Figure 2 is elaborated according to a set of constrains the teachers involved in blended learning sessions reported many times. Most of them aim at the assessment of knowledge assimilated in the self-study activities, face to face lectures, or project documentation, as well as the evaluation of skills and competences during the team projects, hands-on laboratory, or simulation work. For this reason, the authors have taken into consideration the typical web-based knowledge assessment process with its phases, authoring, test delivery, evaluation and feedback, then defined the blended assessment gap in order to model all the inconveniences as a set of functions to be implemented in a flexible blended assessment API (Application Programming Interface). The authors also defined the blended assessment bridge as integrating a set of solutions for such inconveniences. In addition, the bridge has been designed to sustain the creation and continuous update of learners' profiles, as well as the progress monitoring of students during the educational process. At the end of the research phase, the student's profile has been modelled by using a set of parameters that define the interests, learning objectives and study progress, soft skills and technical competences. Nevertheless, the student's profile should be visible for both student and teacher. Thus, the student is able to analyse the own progress regarding whole educational act, while the teacher revises the learner's profile related to the own courses, or laboratory/project, or even an overall profile regarding the class.

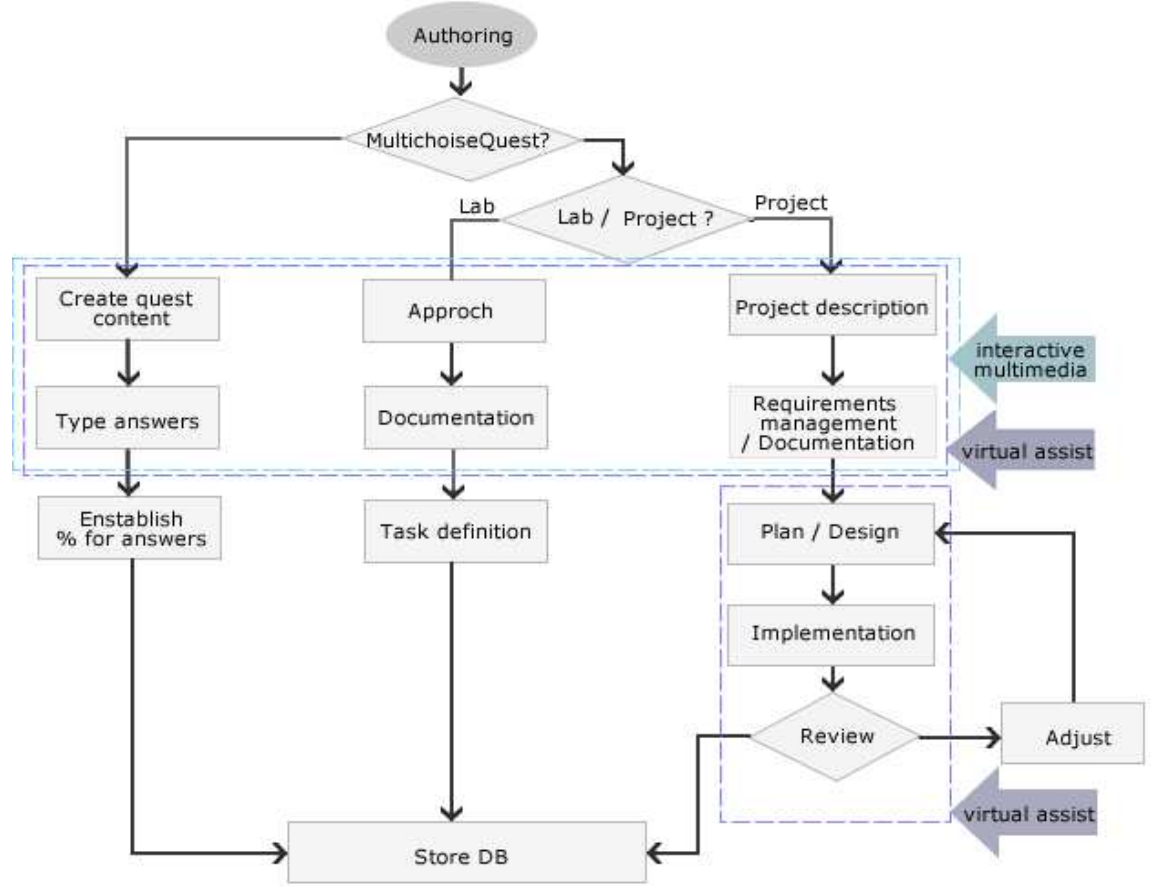

Fig. 2 - Blended assessment model

\section{Blended Learning Framework}

During the live courses, webinar or online tuition, the teacher should be able to share resources, present materials, annotate those materials, share applications and record session. Such presentation usually becomes an open discussion around each subject that involves the teacher and students. The teacher uses the collaborative tools for annotating the materials and combine them with external multimedia elements, share the desktop and applications, all with the main goal of making the educational/training process more effective. In the same manner, the students can actively participate to the educational act by interacting with the class and educational materials, even bringing external resources and sharing them among the class. The blended learning session can be 
recorded and delivered as interactive educational material at will. The entire session is important and should be recorded but the storage and streaming needs imposed the authors to opt for recording the chat, video communication and events that occur within the virtual shared space, application sharing included.

As mentioned, the proposed blended learning framework should provide with complex components that enable a wide range of teaching and learning activities. The hybrid class that extends the real classroom over the Internet and enables the students to actively participate to the teacher's exposure from anywhere is just an example. The framework also allows the teaching staff to create interactive evaluation content and impose the fulfilling criteria, define the assessment schedule and re-plan such activities, if necessary. The interactive elements have their contribution to the assessment effectiveness: the interactive multimedia elements should add value for question and answers, while the virtual assistance has to provide the teaching staff with information regarding the learners' profiles, general interests or study progress.

The knowledge evaluation during the individual and team projects (semester or diploma projects) vary according to the project requirements. When defining the blended assessment model the authors took into consideration the main steps: documentation phase, hands-on activities, simulation processes, applications, tuition, testing, review and adjustments. The students learn how to divide the own project in modules and components, define project versions (releases) according to the project requirements, then establish real steps for each release. The Agile methodologies can be adopted for individual and team projects while they assure the control of the development processes and enable the teachers to correctly evaluate the current results and continuously verify the student's contribution. The authors proposed the iterative development consisting of four main phases: plan and design, implementation, review and adjust. Each phase can be virtually evaluated by the interactive assessment components but the human factor is also necessary, at least for results review and adjustments/suggestions. Thus, the project evaluation can be considered as a combination of capabilities provided by the human factor and intelligent components.

The hands-on laboratory and simulation tasks usually contain small projects to be accomplished in less than two hours, a suggestive documentation of what the student needs to do and the implementation process. Sometimes, the hands-on laboratory and simulation tasks consist of two hours problems to be solved in a real-time manner, by using a short documentation but without teacher's attention. The students start the laboratory work, by reading the documentation, and define a simple work plan. Then they remotely access the allocated virtual machine, via web browser, and accomplish the tasks in the established order. At the end of each task they should complete the activity report and save the work on the storage unit allocated for the own account. The interactive components will count how many times the student review the documentation, the order he/she approaches the tasks and how long the task completion took. Such information will be used for updating the learner's profile with additional skills.

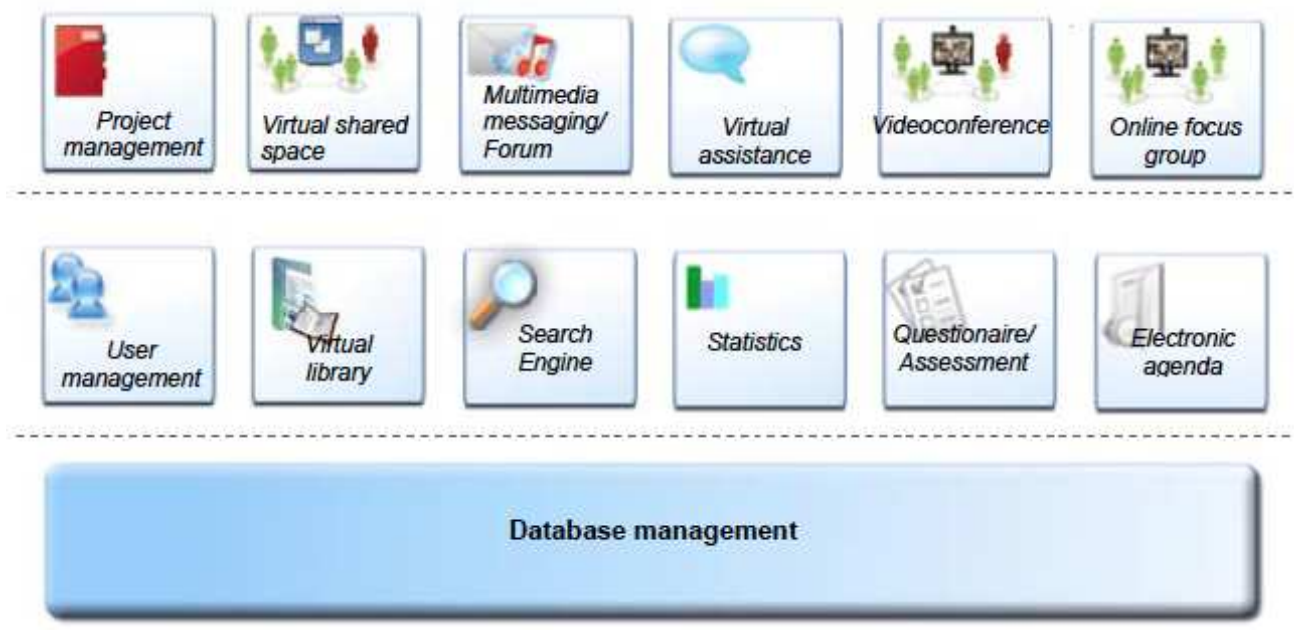

Fig. 3 - Blended learning framework. Block diagram 
We designed a blended learning framework composed by the following modules: user management block (students and teachers), virtual library, search engine, statistics module, electronic agenda, project management module, virtual shared space, multimedia messaging, forum, virtual assistance, videoconferencing tool, and online focus group. The figure 3 illustrates its block diagram and the main components of the blended learning framework.

In order to simplify the development process, the framework is divided in 4 main categories of components: generic components, interpersonal collaborative components, interactive components, and inter-process collaborative components. The generic components implement the main functionalities such as database management, user management, statistics and electronic schedule. Interpersonal collaborative components allow the end-users to actively participate to the collaborative process using the communication tools: multimedia messaging, form, virtual shared space, videoconference, video telephony, online focus group, etc. The interactive components allow the end-users to interact with the system using the natural language. The search engine, virtual library and project management tools are considered as interactive components. Inter-process collaborative components are intelligent components such as business intelligence and virtual assistant that permit the developer to automate the collaborative process in a transparent manner.

The framework development is based on the hybrid architecture illustrated in Figure 4 that extends the LAMP stack (Linux, Apache, MySQL, PHP) and complies with the advantages of SOA (Service Oriented Architecture). The architecture consists of the following blocks: Apache web server, MySQL database server, Flash Media Interactive Server, LibreOffice, GostScript, Ffmpeg and MEncoder libraries. It provides integration functionalities and allows the developers to externalize the media services (Influxis or Amazon EC2) or storage capabilities (virtual library). Apache web server hosts the web components that implement the generic educational functionalities such as authentication, or web access to advanced service; MySQL database server stores the information regarding the lecturers, student and trainees, courses, interactive resources, skills or competences to be achieved, assessment sessions and certifications [11].

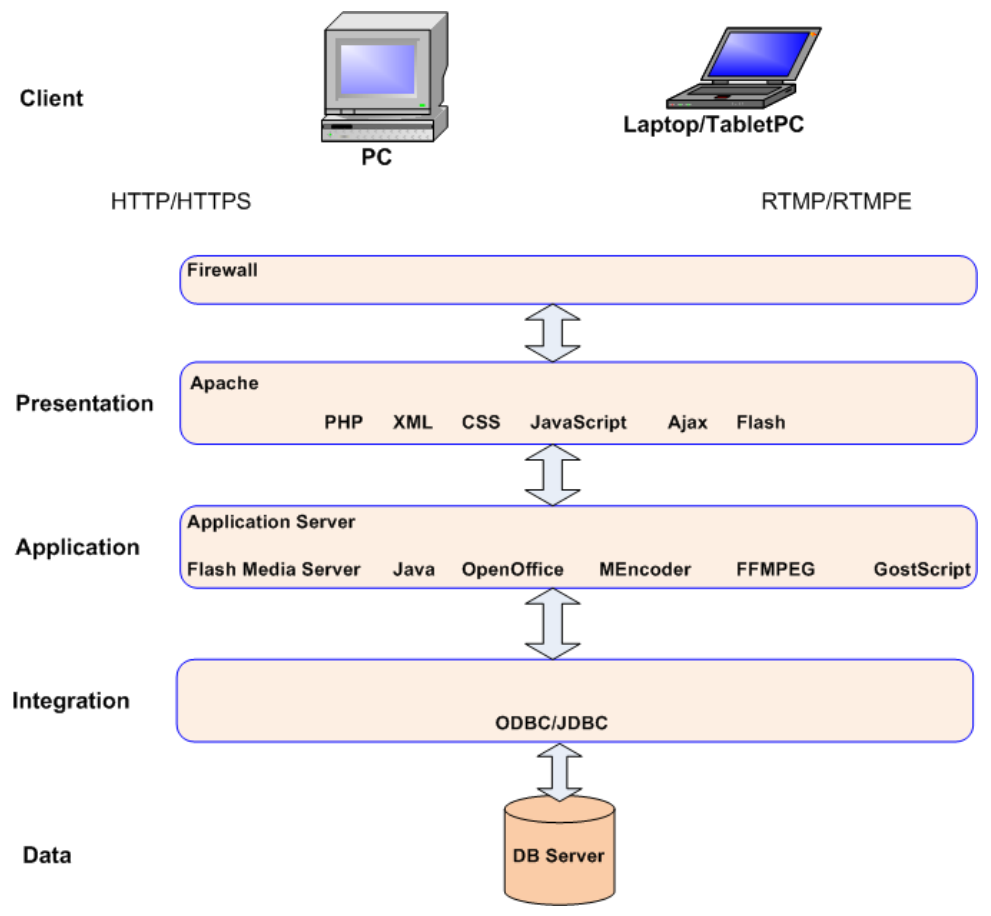

Fig. 4 - Blended learning framework. Hybrid architecture

Flash media interactive server provides with video conferencing and virtual collaboration capabilities, media streaming and video capture/recording features, as well as remote shared objects support. The virtual library consists of the storage component, conversion block and resource management tools. The educational/training resources are converted from original formats to internal symbols and integrated as slideshow then stored into the virtual library. The conversion 
block is composed by two different components: the document convertor and the media convertor. While the document convertor is a Java-based component that uses LibreOffice and GostScript libraries for converting MS formats or pdf files to slideshow, the media convertor uses MEncoder and FFmpeg capabilities for converting the multimedia elements to flv or $\mathrm{f} 4 \mathrm{v}, \mathrm{mp} 3$, or $\mathrm{mp} 4$ formats. This way, the virtual library supports most of the file formats and the internal service handler component can manage the digital content in a unified manner.

The rich user interface (RUI) concept increases the degree of interactivity and makes the content presentation transparent by network and user or education types. The most important aspect to be taking into consideration is actually its contribution to the cyberspace into which the real educational environment and the online platform are integrated through the blended learning bridge, where the teachers and students can accomplish their tasks without special IT skills. Figure 5 illustrates the invocation mechanism and underlines the manner the information is interactively presented to the end-users.

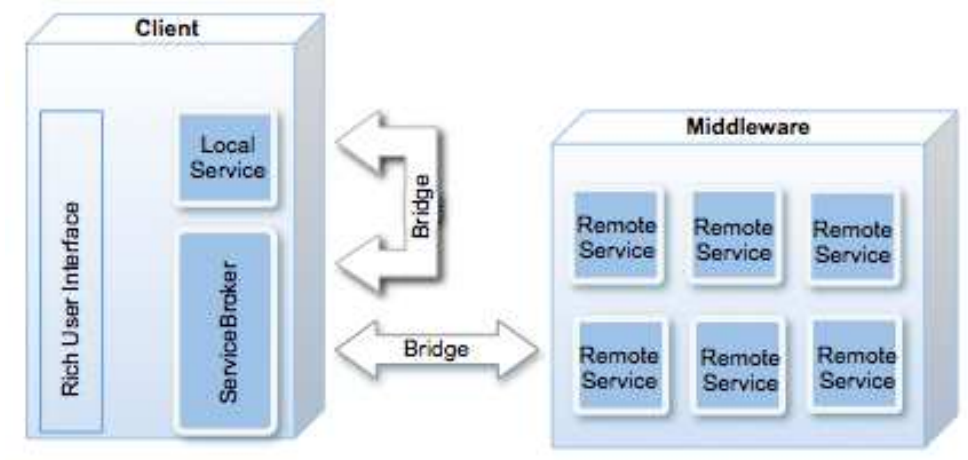

Fig. 5. Blended learning framework. Service invocation mechanism.

The RUI components consist of controls and buttons that generate different events and 2/3D view scenes used for content presentation. Each RUI component is responsible for handling the events and the data model needed for local transactions. Once the model is created, the controller can impose the data collection to the mediator that calls the service broker in order to retrieve the service descriptors. The remote service is invoked, the bridge component routes the service response to mediator that establishes which methods the controller should invoke and their order, and then the view component displays the information to the end-user.

\section{Experimental Results}

The approach was implemented as a pilot project that includes the course of Multimedia Technologies in the Faculty of Electronics, Telecommunications and Information Technology within the Technical University of Cluj-Napoca (TUCN), as well as the course for diploma preparation in the same field of Multimedia Technologies. If the faculty course requires blended teaching, problem-based learning and blended assessment support, the second one includes blended teaching, project-based learning and project evaluation.

The teachers involved in the pilot project are experienced with the novel methodologies for creating and delivering the educational content during the collaborative learning sessions, as well as the use of such innovative teaching technologies as online tuition or webinar tools, course authoring, video and screen recording, annotation instruments. Most of students, more than $85 \%$, possess IT skills and consider the blended learning environment as the only one way to work closely to the teacher that leads his/her diploma project. In this way, when testing the blended learning framework in our university we aimed at demonstrating the needs of implementing such infrastructure for continuously working with our students even outside the faculty labs. During the testing sessions, we identified some important requests from both participants in the educational process.

The first challenge was related to enabling students to learn and work in a well-organized manner having remote access to any information or educational resources and to collaborate with the teachers and other colleagues, if they are part of the same project or working independently. This 
fact promotes the collaborative learning perception as more complex than team projects, video conferencing sessions and students/trainees connected with teachers/trainers from home or work place. For this reason, the blended learning framework provides teachers and students with an intuitive and well-organized graphical user interface exposed by flexible and interactive client-side components that implement the blended learning bridge. In addition, the client-side components support virtual and face-to-face collaboration between teachers and students during the teaching act, as well as between students during the practice activities. Figure 6 illustrates the manner the teacher conducts a blended learning process that involves students in real classroom and others virtually attending the session. Such software module that implements the bridge between real educational classroom and Internet-based learning environment is called hybrid classware and can be easily customized for different educational domains.

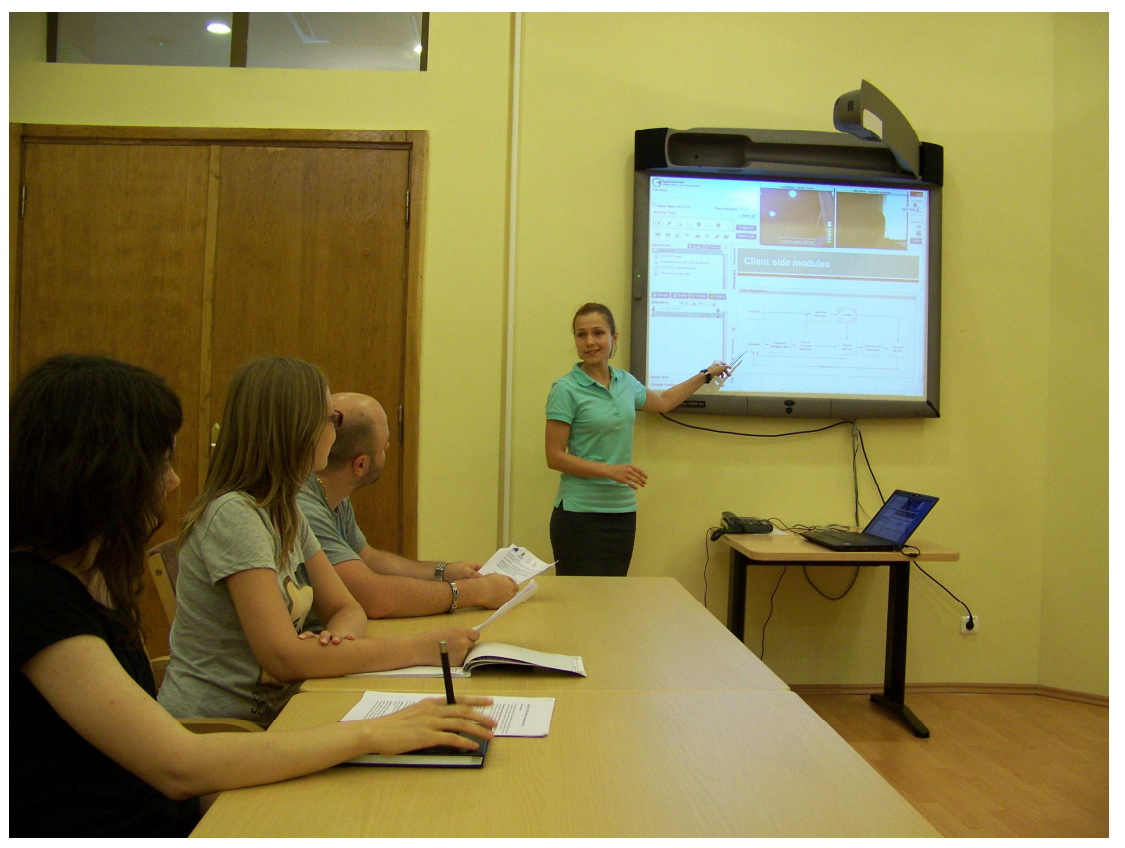

Fig. 6 - Hybrid classware

The second challenge has been raised by teachers conducting semester and diploma projects in new exciting fields that needed more documentation and teachers' support from the beginning to the final presentation. In such an educational act, the students must assimilate new information and extract the knowledge that facilitates the tasks completion as well as presentation of achieved results to the other colleagues and teaching staff. So, a customized hybrid classware component that provides with collaborative learning and work capabilities has been proposed. It also enabled teachers to conduct blended assessment sessions with the main goal of measuring the students' study progress during the project phases. The same approach is also implemented for evaluation tasks during the wide classes extended outside the classroom/laboratory (Figure 7). During the teacher's exposure, a quick can be launched by setting up several parameters such as questions to be delivered, number of option choices and time to answer the selected question, then the students will answer the question and the average result will be displayed to the teacher.

The third challenge was regarding the completion of hands-on laboratory activities and semester project tasks where the teachers are constrained to accomplish not confortable redundant tasks and continuous verification of each student's contribution to the common activities. In addition, the students raised their main problem related to the work from home for completing the lab activities and project tasks. In this way, the blended learning framework integrates a set of educational tools that enable teachers to create interactive tutorials and record simulation processes, control and assess the virtual and remote laboratory tasks. From the student's point of view, the framework presents the interactive components that allow remote access to the laboratory infrastructure for task completion. The evaluation of students' contributions during the laboratory activities or project phases cannot be $100 \%$ realized in an automatic mode. There are intelligent components responsible 
for interpreting the manner each student accomplishes the laboratory and project tasks, by estimating the student's effort for each task, then updating his/her profile and study progress, but it also needs the teacher's attention. In this way, the blended learning framework is extended with two more collaborative tools to be used for project and laboratory assessment activities. The first one is involved when students and teachers are working together in a project phase or when the teacher manually evaluates the student's tasks in the lab process or project tasks. The other should continuously evaluate the student's lab activities or project tasks and update his/her profile in order to provide the teachers with the correct information about the working progress, student's soft and technical skills, or his/her behaviour during the laboratory or project phases. Such tools were appreciated by most of the teaching staff while the redundant activities are avoided, as well as by all the students able to accomplish their practice activities remotely.

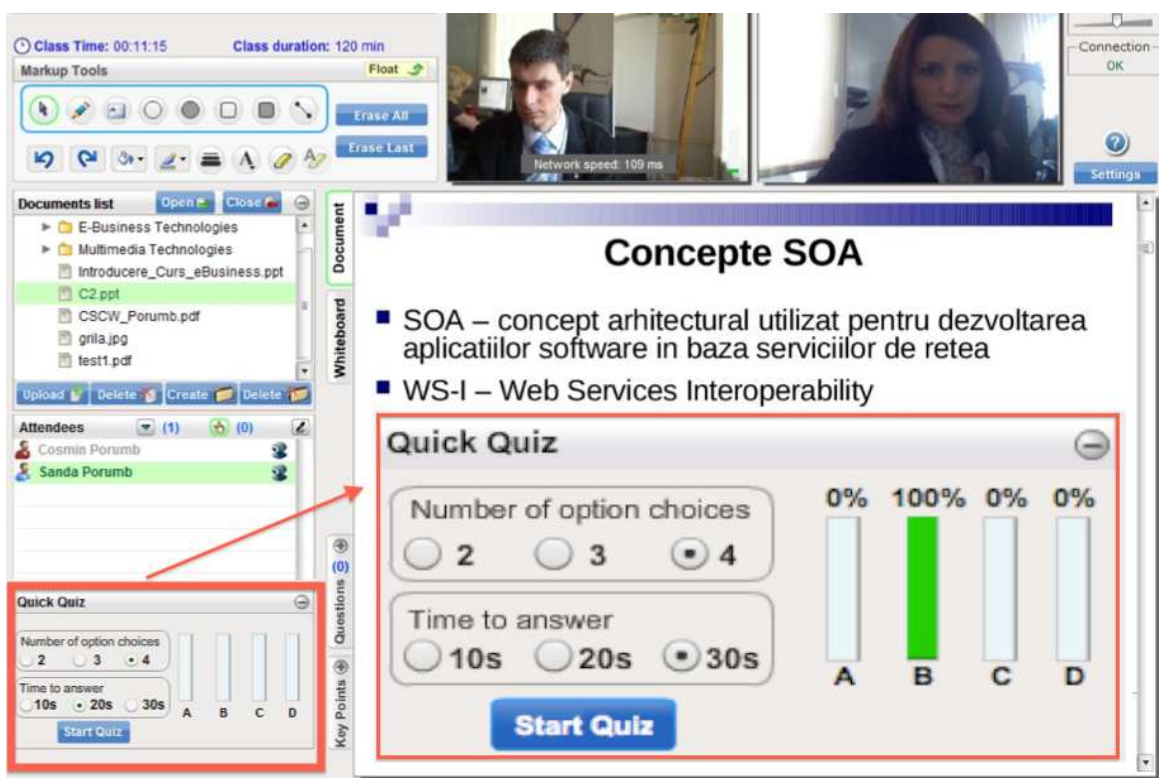

Fig. 7 - Blended assessment session

\section{Conclusions}

The paper describes important solutions for the problems experienced when adopting several enhanced blended learning methods in engineering education. After defining the blended learning model, the authors illustrate its implementation within an infrastructure dedicated engineering education. The approach was implemented as a pilot project that includes the course of Multimedia Technologies in the Faculty of Electronics, Telecommunications and Information Technology within the Technical University of Cluj-Napoca (TUCN), as well as the course for diploma preparation in the same field of Multimedia Technologies.

During the testing sessions, some important requests from both participants in the educational process have been identified. The first problem was related to enabling students to learn and work in a well-organized manner having remote access to any information or educational resources and to collaborate with the teachers and other colleagues in the same project or working independently. The solution consists of the implementation of the bridge between real educational classroom and Internet-based learning environment within the hybrid classware and its adoption in different educational domains. The second problem has been raised by teachers conducting semester and diploma projects. In such an educational act, the students must assimilate new information and extract the knowledge that facilitates the tasks completion as well as presentation of achieved results to the other colleagues and teaching staff. The customization of hybrid classware component in order to provide with collaborative learning and work capabilities, as well as blended assessment has been proposed. The third problem was regarding the completion of hands-on laboratory activities and semester project tasks where the teachers are constrained to accomplish not comfortable redundant tasks and continuous verification of student's contribution to the common 
activities. Simultaneously, the students raised their main problem related to the work from home for completing the lab activities and project tasks. In this way, the blended learning framework integrates a set of educational tools that enable teachers to create interactive tutorials and record simulation processes, control and assess the virtual and remote laboratory tasks.

\section{Acknowledgement}

This paper was supported by the project "Development and support of multidisciplinary postdoctoral programmes in major technical areas of national strategy of Research - Development Innovation" 4D-POSTDOC, contract no. POSDRU/89/1.5/S/52603, project co-funded by the European Social Fund through Sectoral Operational Programme Human Resources Development 2007-2013.

\section{References}

Reference an article:

[1] S. Thamarai Selvi, P. Perumal, Blended learning for programming in cloud based e-Learning system, Proceedings of the ICRTIT Conference - Recent Trends In Information Technology, (2012) 197-201.

[2] R. Manseur and Z. Manseur, A Synchronous Distance Learning Program Implementation in Engineering and Mathematics, Proceedings of the $39^{\text {th }}$ ASEE/IEEE Frontiers in Education Conference, San Antonio, Texas, (2009) 1-6.

[3] M. Qiu, and L. Chen, A Problem-based Learning Approach to Teaching an Advanced Software Engineering Course, Proceedings of the 2nd International Workshop on Education Technology and Computer Science, (2011) 252-255.

[4] K. Sugawara, S. Fujita, and H. Hara, A Concept of Symbiotic Computing and its Application to Telework, Proceedings of the $6^{\text {th }}$ IEEE Int. Conf. on Cognitive Informatics (2007) 302-311.

[5] T. Kuroda, A. Sakatoku, G Kitagata, D. Chakraborty, and Norio Shiratori, Open 3D Shared Space Construction Scheme for Symbiotic CollaborativeWorks, Proceedings of the 28th International Conference on Distributed Computing Systems Workshops, (2008) 78-83.

[6] S. Leone, T. Leo, and N. Chen, An integrated model of synchronous cyber assessment and blended learning environment for foreign language learners, Proceedings of the 10th IEEE International Conference on Advanced Learning Technologies, (2010) 110-112.

[7] J.E. Mitchell, B. Canavan, and J. Smith. "Problem-based learning in communication systems: student perceptions and achievement", IEEE Transactions on education, (2010), Volume: 53, Issue: $4,587-594$.

[8] M. Llamas-Nistal, M. Caeiro-Rodriguez, and M. Castro. "Use of e-learning functionalities and standards: the Spanish case", IEEE Transactions on education, (2011), Volume: 54, Issue: 4, 540-549.

[9] L. Shaozi, Q. Zhongpan, L. Tangqui, C. Huowang, Architecture of computer supported collaborative learning based on EJB middleware and it's implementation, Proceedings of the $8^{\text {th }}$ International Conference on Computer Supported Cooperative Work in Design. Vol. 1 (2003) 142-148.

[10]A. Aguilar, A. de Antonio, and R. Imbert, An intelligent collaborative environment for team training - A preliminary report", Proceedings of the $15^{\text {th }}$ International Conference on Computing (2006) 236-239.

Reference to a chapter in an edited book:

[11]C. Porumb, S. Porumb, B. Orza, A. Vlaicu, Collaborative learning tools in higher education and lifelong learning, in: P. Isaias, D. Ifenthaler, K. Sampson, and J.M.G. Spector. "Towards learning and instruction in Web 3.0", Springer Publishing House, 2011, pp 89-105. 